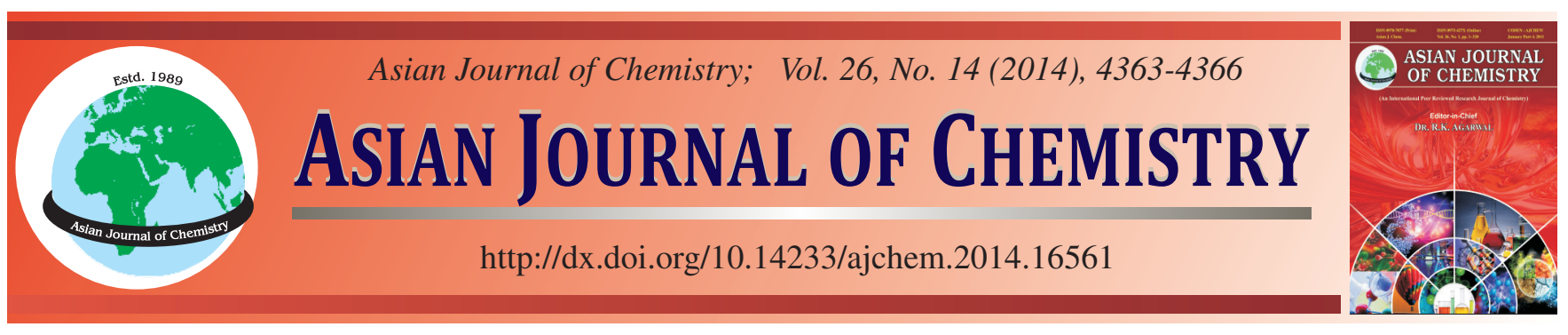

\title{
Simultaneous Determination of Nitrate and Nitrite in Wrapper by High-Performance Liquid Chromatography with Cloud-Point Extraction
}

\author{
XiaOlan $\mathrm{Li}^{1}$, Dongling Meng ${ }^{1}, \mathrm{~J}_{\mathrm{iaO}} \mathrm{ZhaO}^{2}$ and Yaling Yang ${ }^{1, *}$
}

${ }^{1}$ Technology Centre of China Tobacco Guangxi Industrial Co., Ltd., Nanning 530001, Guangxi Province, P.R. China ${ }^{2}$ College of Life Science and Technology, Kunming University of Science and Technology, Kunming 650105, P.R. China

*Corresponding author: E-mail: yilyi18@163.com; 892418937@qq.com

\begin{abstract}
A simple, fast, sensitive and accurate reversed-phase HPLC methodology for simultaneous monitoring of nitrate and nitrite in wrapper is described. Nitrite was determined directly using the Griess diazo-coupling reaction and the formed azo dye was measured at $510 \mathrm{~nm}$ by HPLC with cloud point extraction. Nitrate based on the ion pair chromatography to be quantified by HPLC when UV light absorption responses at $210 \mathrm{~nm}$. Ultrasonic-assisted extraction was utilized to reduce extraction time and improve extraction efficiency when nitrate and nitrite were extracted from the paper. The effective parameters of the extraction process such as ultrasonic auxiliary extraction time, the volume of nonionic surfactant (Triton X-114), sample $\mathrm{pH}$, ionic strength, equilibration temperature and time were optimized. Under the optimum conditions, this method was characterized by an acceptable linear range of 5 to $800 \mathrm{ng} / \mathrm{mL}$ for nitrite, 0.1 to $10 \mu \mathrm{g} / \mathrm{mL}$ for nitrate and correlation coefficients of the calibration curves were both higher than 0.996 . The limits of detection are $5 \mathrm{ng} / \mathrm{mL}$ and 100 $\mathrm{ng} / \mathrm{mL}$ for nitrite and nitrate respectively. The proposed method was successfully applied to the extraction and determination of nitrite and nitrate in wrapper and the satisfactory relative recoveries (86.1-96.6\%) were obtained.
\end{abstract}

Keywords: Nitrite, Nitrate, Cloud point extraction, High-performance liquid chromatography, Wrapper.

\section{INTRODUCTION}

Nitrite and nitrate are ubiquitous within environmental, food manufactures, other industrial processes and biological fluids ${ }^{1}$. Packaging materials, such as cigarette paper also contains nitrite and nitrate, and characteristics of cigarette paper directly affect the combustibility, aroma components and flavor of cigarette ${ }^{2}$. The simultaneous determination and speciation of nitrite and nitrate have increasing attention in recent years because of their potential harmful impact on human health. Many analytical methods for the determination of nitrite and nitrate have been developed, including spectrophotometry $^{3-6}$, spectrofluorimetry ${ }^{7-11}$, gas chromatography ${ }^{12,13}$, high performance liquid chromatography ${ }^{14,15}$, capillary electrophoresis ${ }^{16}$, flow injection analysis ${ }^{17}$ and ion chromatography ${ }^{18}$. However, they are limited for cross-reactivity and poor interlaboratory reproducibility. Furthermore, some methods needed complicated procedures of extraction or expensive instruments. The commonly used methods for nitrite determination include the spectrophotometric detection based on the Griess reaction ${ }^{19}$, in which nitrite is diazotized with sulfanilamide and then reacted with N-(1-naphthyl)ethylenediamine to form a colored product. For the measurement of concentration of nitrate, it is necessary to reduce the nitrate to nitrite with copperised cadmium and the process of reduction is very complicated and time-consuming ${ }^{20}$. In addition, nitrite is usually present in paper in relatively low amounts compared to nitrate anion and its concentration falls under the detection limit. Because of this, a cloud point extraction was used to quantify the trace nitrite.

The goal of this paper was to obtain a simple, sensitive, fast and cost-effective method for the detection of nitrite and nitrate in wrapper. In the present study, a commonly available and easy to operate method was to develop for analyzing the nitrite and nitrate in wrapper by cloud point extraction using Triton X-114 as the extraction solvent.

\section{EXPERIMENTAL}

Experiments were performed using a HPLC system consisting of a vacuum degasser, an auto sampler, a quaternary pump and a diode-array detector (Agilent 1200 Series, Agilent Technologies, Calif, USA). An ultrasonic cleaner with temperature control (Shanghai, China) was used for ultrasonic extraction. A centrifuge with calibrated centrifugal tubes (Shanghai, China) was used for the phase separation process.

Standards of sodium nitrite and sodium nitrate were purchased from Aladdin Chemical Co. (Shanghai, China). 
Acetonitrile and methanol were chromatographic grade (Tedia Company, USA). Except where noted, all reagents were of analytical grade and all solution preparations were made using doubly distilled-deionized water. Several different kinds of wrappers were purchased from local supermarket.

High performance liquid chromatography-DAD detection: Chromatographic separations were carried out using a reversed phase C18 analytical column of $150 \times 4.6 \mathrm{~mm}$ (Agilent TC-C18). The mobile phase consisted of acetonitrile, methanol and doubly distilled-deionized water contained $1 \%$ (v/v) tetrabutylammonium hydroxide (Aladdin, China) at $\mathrm{pH} 4$. The gradient elution program was shown in Table-1. To get the optimum results, mobile phase with a flow rate of $1 \mathrm{~mL} / \mathrm{min}$ and column temperature at $25^{\circ} \mathrm{C}$ were used. The injection volume was $20 \mu \mathrm{L}$ and the DAD detector was set at 220 and $510 \mathrm{~nm}$ which are the proper absorption wavelengths of nitrate and nitrite, respectively.

\begin{tabular}{cccc}
\multicolumn{5}{c}{ TABLE-1 } \\
GRADIENT ELUTION PROGRAM OF HPLC \\
\hline $\begin{array}{c}\text { Time } \\
(\mathrm{min})\end{array}$ & $\begin{array}{c}\text { Acetonitrile } \\
(\%)\end{array}$ & $\begin{array}{c}\text { Methanol } \\
(\%)\end{array}$ & $\begin{array}{c}1 \% \text { Tetrabutylammonium } \\
\text { hydroxide }(\%)\end{array}$ \\
\hline 0 & 10 & 0 & 90 \\
5.0 & 10 & 0 & 90 \\
7.0 & 10 & 46 & 44 \\
11.0 & 10 & 46 & 44 \\
12.0 & 10 & 0 & 90 \\
\hline
\end{tabular}

Preparation of solutions: Standard stock solutions of nitrate and nitrite were prepared by dissolving dried sodium nitrate and sodium nitrite (at $110^{\circ} \mathrm{C}$ for $2 \mathrm{~h}$ ) in doubly distilleddeionized water at a concentration of $500 \mu \mathrm{g} / \mathrm{mL}$. Working solutions were prepared by an appropriate dilution of the stock solutions on the day of use. Griess A reagent, $100 \mathrm{mg} p$-aminobenzene sulfonic acid was dissolved in a mixture consisting of $5 \mathrm{~mL}$ acetic acid and $5 \mathrm{~mL}$ purified water by water bath heating $\left(45^{\circ} \mathrm{C}\right)$. Griess B reagent was prepared by dissolving $10 \mathrm{mg}$ 1-naphtylamine in $10 \mathrm{~mL}$ acetic acid. $10 \mathrm{~mL}$ of Triton X-114 (Sigma, USA) was dissolved in $100 \mathrm{~mL}$ double distilleddeionized water for a Triton X-114 (10\%).

Preparation of sample: $0.2 \mathrm{~g}$ wrapper was weighed accurately and placed in a screw-cap glass centrifuge tube with a conical bottom with $10 \mathrm{~mL}$ doubly distilled-deionized water. The centrifuge tube was placed in ultrasonic cleaner at $25 \mathrm{kHz}$ of ultrasonic frequency and $25^{\circ} \mathrm{C}$ for $10 \mathrm{~min}$. The extraction solution was filtered using qualitative filter paper into a new tube. Afterwards, $\mathrm{pH}$ of sample was adjusted to $\mathrm{pH} 5$ by the addition of dipotassium hydrogen phosphate-potassium dihydrogen phosphate buffer solution. The $5 \mathrm{~mL}$ extraction solution was subjected to the cloud-point extraction procedure.

Cloud-point extraction procedure: A $5 \mathrm{~mL}$ prepared extraction solution of paper containing nitrite was placed in a screw-cap glass centrifuge tube with a conical bottom. Then $100 \mu \mathrm{L}$ of Triton $\mathrm{X}-114$ and $0.3 \mathrm{~g}\left(\mathrm{NH}_{4}\right)_{2} \mathrm{SO}_{4}$ were added into the sample solution and mixing uniformity by vortex. A cloudy solution was formed after the solution was placed in a thermostat bath at $45^{\circ} \mathrm{C}$ for $10 \mathrm{~min}$. After centrifugation at $4000 \mathrm{rpm}$ for $10 \mathrm{~min}$, the emulsion was detached. The aqueous phase was removed and the surfactant-rich phase was deposited at the bottom of the tube. Then the surfactant-rich phase was diluted to $0.4 \mathrm{~mL}$ with methanol and sample was filtered through $0.45 \mu \mathrm{m}$ nylon syringe filter (troody, China) in order to remove particles. $20 \mu \mathrm{L}$ of solution was injected into the HPLC system for analysis. A blank solution was also run using water instead of nitrite.

\section{RESULTS AND DISCUSSION}

The variables investigated were extraction way and the type of ion pair reagent, volume of Triton $\mathrm{X}-114, \mathrm{pH}$, the addition of $\left(\mathrm{NH}_{4}\right)_{2} \mathrm{SO}_{4}$, the equilibration temperature. Quantitation was carried out by the peak area method. In this experiment, $5 \mathrm{~mL}$ of prepared sample spiked with $5 \mu \mathrm{g} / \mathrm{mL}$ of nitrate and $100 \mathrm{ng} / \mathrm{mL}$ of nitrite was used for the study. All the experiments were performed 5 times and the averages of the results were used for optimization.

Effect of sonication time: Ultrasound has been used to induce physical or chemical effects in a medium by using lowfrequency ultrasound for a period time. This extraction can be accelerated by ultrasonic waves and experiments show the enhancement of the absorbance in the presence of ultrasonic waves. The ultrasonic time was also investigated. It was found that an exposure time of $10 \mathrm{~min}$ is enough for the best sensitivity.

Effect of sample pH: An acid medium is necessary for $\mathrm{NO}_{2}{ }^{-}$reacts with Griess reagent to form diazo compound, but too excessive amount of $\mathrm{H}^{+}$is disadvantageous to extraction efficiency. The effect of $\mathrm{pH}$ on the absorbance at a constant concentration of nitrite in surfactant-rich phase was investigated in the range 3-7. As can be Fig. 1, the highest signal intensity of nitrite was obtained at $\mathrm{pH}$ 5. Therefore the optimum $\mathrm{pH}$ was used as 5 in the experiment.

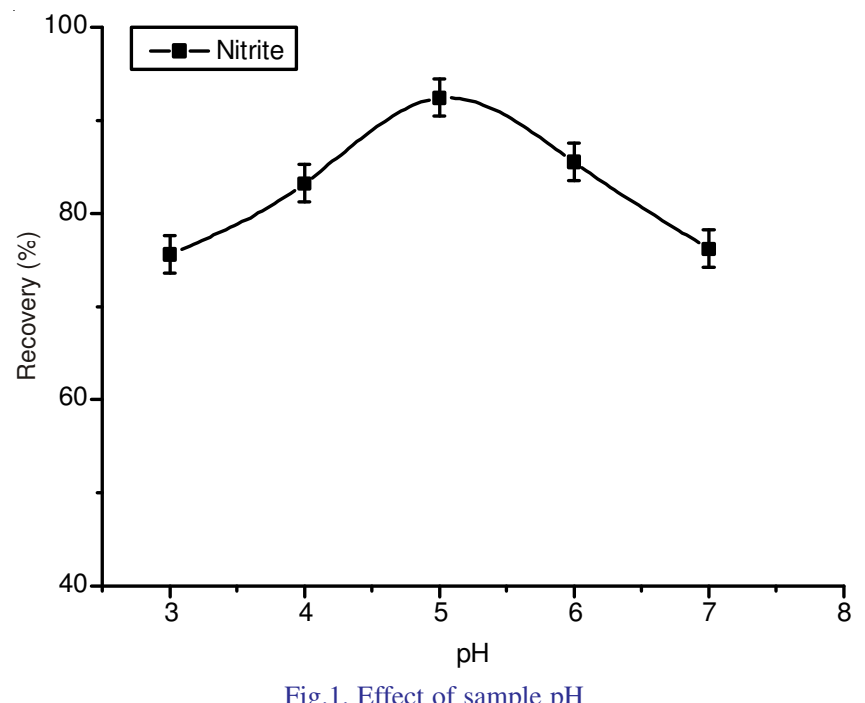

Effect of Triton X-114 concentration: The surfactant concentration is a critical factor for effective extraction and should be sufficient for quantitative extraction of the trace nitrite. The extraction solvent should have similar hydrophobicity to the target analytes and form a stable cloudy system with the presence of Triton X-114 and $\left(\mathrm{NH}_{4}\right)_{2} \mathrm{SO}_{4}$. The effect of the concentration of Triton X-114 on the extraction efficiency was investigated in the range 0.2-1.8\% (v/v). As Fig. 2 shows, $1 \%$ Triton $\mathrm{X}-114$ was selected in the subsequent experiments. 


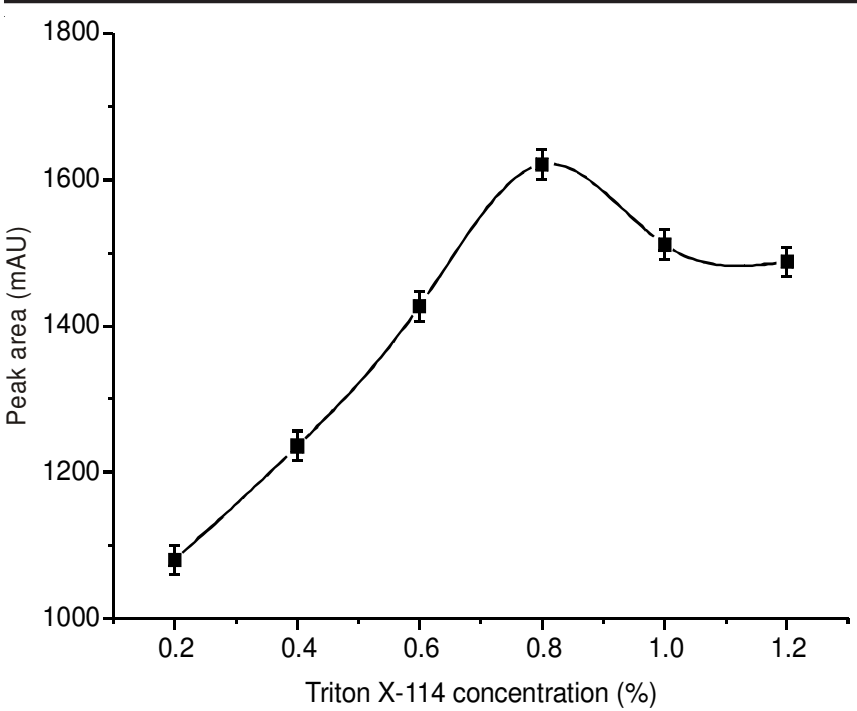

Fig. 2. Effect of Triton X 114 concentration

Effect of salt amount: The addition of salt can increase the incompatibility between the water structures in hydration shells of ions and surfactant macromolecules. Addition of salt can decrease the cloud-point temperature and accelerate the phase separation by enhancing the micellar concentration in the surfactant-rich phase. The addition of $\left(\mathrm{NH}_{4}\right)_{2} \mathrm{SO}_{4}$ was investigated in the concentration range of $0.1-05 \mathrm{~g}$. AS shown in Fig. 3. The adequate addition of $\left(\mathrm{NH}_{4}\right)_{2} \mathrm{SO}_{4}$ is $0.3 \mathrm{~g}$ to achieve quantitative extraction.

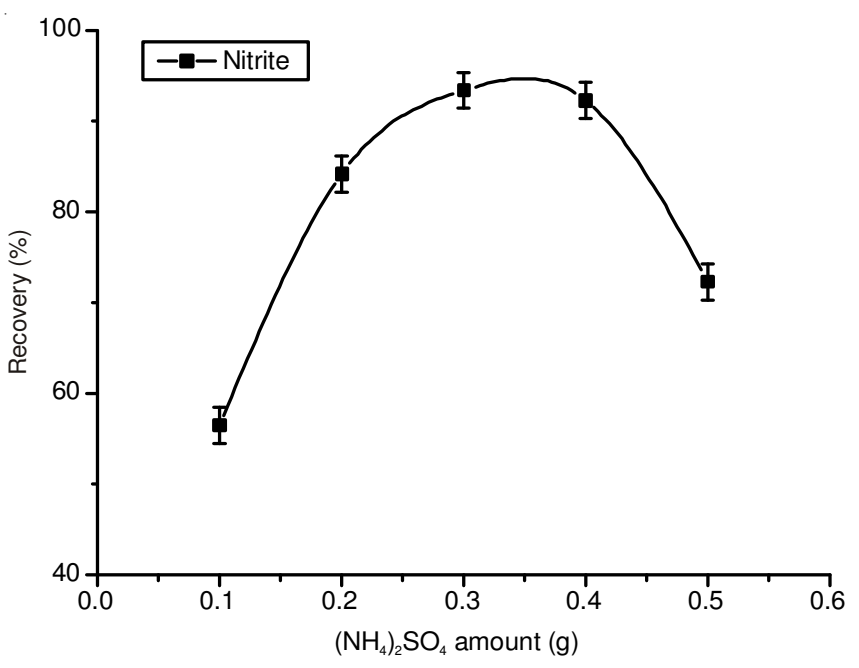

Fig. 3. Effect of salt amount

Effect of the equilibration temperature and time: Equilibration time and equilibration temperature are two important parameters in cloud point extraction. It was desirable to employ the shortest equilibration time and the lowest possible equilibration temperature as a compromise between completion of extraction and efficient separation of phases. The dependence of extraction efficiency upon equilibrium temperature and time was studied over ranges of $30-70{ }^{\circ} \mathrm{C}$ and $10-$ $50 \mathrm{~min}$, respectively. The results showed that an equilibrium temperature of $45^{\circ} \mathrm{C}$ is appropriate and $10 \mathrm{~min}$ as equilibration time is enough for nitrite derivatives in order to achieve quantitative extraction.
Characteristics of analytical method: Table- 2 shows some analytical characteristics of the optimized method, including regression equation, linear range, limits of detection and enrichment factors. The linearity of nitrite was in the range $5-800 \mathrm{ng} / \mathrm{mL}$ and of nitrate in the range $0.1-10 \mu \mathrm{g} / \mathrm{mL}$. The detection limits were $5 \mathrm{ng} / \mathrm{mL}$ for nitrite and $100 \mathrm{ng} / \mathrm{mL}$ for nitrate, respectively. The relative standard deviation (RSD) of 100 and $5 \mu \mathrm{g} / \mathrm{mL}$ for nitrite and nitrate was less than $4.5 \%$.

\begin{tabular}{cccccc}
\multicolumn{7}{c}{ TABLE-2 } \\
\multicolumn{7}{c}{$\begin{array}{c}\text { PERFORMANCE CHARACTERISTICS } \\
\text { OF THE PROPOSED METHOD }\end{array}$} \\
\hline Analyte & $\begin{array}{c}\text { Regression } \\
\text { equation }\end{array}$ & $\begin{array}{c}\text { Linear } \\
\text { range } \\
(\mathrm{ng} / \mathrm{mL})\end{array}$ & $\begin{array}{c}\text { RSD } \\
(\%) \mathrm{n}=6\end{array}$ & $\mathrm{r}^{2}$ & $\begin{array}{c}\text { Limit of } \\
\text { detection } \\
(\mathrm{ng} / \mathrm{mL})\end{array}$ \\
\hline Nitrate & $\mathrm{Y}=1.34 \mathrm{X}+89.114$ & $10-5000$ & 4.33 & 0.9980 & 100.0 \\
Nitrite & $\mathrm{Y}=14.76 \mathrm{X}+14.571$ & $5-800$ & 3.85 & 0.9961 & 5.0 \\
\hline
\end{tabular}

Application: The accuracy and validity of the proposed method was checked by applying the determination of nitrite and nitrate concentration in various wrapper samples. Recovery studies were also carried out after it was spiked to samples known concentrations of nitrite at levels of 100 and $300 \mathrm{ng} / \mathrm{g}$ and of nitrate at levels of 5 and $10 \mu \mathrm{g} / \mathrm{g}$. The accuracy, precision and reproducibility were verified by recovery studies. As presented in Tables 3 and 4, the recoveries for the addition of different concentrations of nitrite and nitrate to samples are in the range of $86.1-96.6 \%$. The results show that the proposed method is effective for the determination of trace amounts of nitrate and nitrite in the real cigarette paper samples.

TABLE-3

NITRATE AND NITRITE FOUND IN WRAPPER SAMPLES AND RECOVERIES OBTAINED AFTER SPIKING THE SAMPLES WITH NITRATE AND NITRITE AT TWO CONCENTRATION LEVELS

\begin{tabular}{ccc|cc|cc}
\hline \multirow{2}{*}{ Sample } & \multicolumn{2}{c|}{ Spiked } & \multicolumn{2}{c|}{ Found } & \multicolumn{2}{c}{ Recovery $(\%)$} \\
\cline { 2 - 7 } & $\begin{array}{c}\text { Nitrite } \\
(\mu \mathrm{g} / \mathrm{mL})\end{array}$ & $\begin{array}{c}\text { Nitrate } \\
(\mathrm{ng} / \mathrm{mL})\end{array}$ & $\begin{array}{c}\text { Nitrite } \\
(\mathrm{ng} / \mathrm{mL})\end{array}$ & $\begin{array}{c}\text { Nitrate } \\
(\mu \mathrm{g} / \mathrm{mL})\end{array}$ & $\begin{array}{c}\text { Nitrite } \\
(\mathrm{ng} / \mathrm{mL})\end{array}$ & $\begin{array}{c}\text { Nitrate } \\
(\mu \mathrm{g} / \mathrm{mL})\end{array}$ \\
\hline 1 & 0.0 & 0.0 & $10.63 \pm 0.1$ & $4.82 \pm 0.04$ & & \\
& 100.0 & 5.0 & $108.22 \pm 0.1$ & $9.12 \pm 0.1$ & 88.6 & 86.1 \\
& 300.0 & 10.0 & $300.51 \pm 0.1$ & $13.53 \pm 0.1$ & 96.6 & 87.1 \\
\hline 2 & 0.0 & 0.0 & $18.7 \pm 0.2$ & $3.56 \pm 0.1$ & & \\
& 100.0 & 5.0 & $112.57 \pm 0.1$ & $8.12 \pm 0.2$ & 92.8 & 91.2 \\
& 300.0 & 10.0 & $298.35 \pm 0.1$ & $12.35 \pm 0.1$ & 93.2 & 87.9 \\
\hline
\end{tabular}

\begin{tabular}{|c|c|c|c|}
\hline \multicolumn{4}{|c|}{$\begin{array}{l}\text { TABLE-4 } \\
\text { NITRATE AND NITRITE FOUND IN BLANK WRAPPER } \\
\text { SAMPLES, AND RECOVERIES OBTAINED }\end{array}$} \\
\hline & \multicolumn{3}{|c|}{ Samples } \\
\hline & 1 & 2 & 3 \\
\hline Nitrite (ng/mL) & 0.014 & 0.024 & 0.022 \\
\hline Nitrate $(\mu \mathrm{g} / \mathrm{mL})$ & 4.67 & 3.48 & 5.22 \\
\hline
\end{tabular}

\section{Conclusion}

The new proposed procedure gives a sensitive and selective for the determination of nitrate and nitrite ions in wrapper samples. In this study, ion pair chromatography was developed for direct determination for nitrate. The cloud point extraction preconcentration was used to analysis the trace nitrite. The results indicate the method has high recovery and good repeatability, 
short extraction time and good linearity over the investigated concentration range. The use of easily available equipments, low cost, easy sample preparation and better performance than the other published methods is the superiority of this method. The results showed that the nitrite and nitrate could be effectively monitored by this method and it was also a good reference for wrapper.

\section{ACKNOWLEDGEMENTS}

The work was greatly supported by the Medical Neurobiology Key Laboratory of Kunming University of Science and Technology, Basic and Applied Research Project in Yunnan province (2012ZC082M) and the Analysis and Testing Foundation of Kunming University of Science and Technology (No. 2012121).

\section{REFERENCES}

1. M.D. Croitoru, J. Chromatogr. B, 911, 154 (2012).

2. Y.J. Tao, W.Q. Gao, L. Zh. Liu and R. Liu, Tobacco Sci. Technol., 04, (1995).

3. M.S. Abdul Galil, Mahadevaiah, M.S. Yogendra Kumar and G.
Nagendrappa, Spectrochim. Acta A, 67, 76 (2007).

4. A. Aydin, O. Ercan and S. Tascioglu, Talanta, 66, 1181 (2005).

5. X.F. Yue, Z.Q. Zhang and H.T. Yan, Talanta, 62, 97 (2004).

6. A. Afkhami, T. Madrakian and A. Maleki, Anal. Biochem., 347, 162 (2005).

7. J.S. Li, H. Wang, X. Zhang and H.S. Zhang, Talanta, 61, 797 (2003).

8. Q.H. Liu, X.L. Yan, J.C. Guo, D.H. Wang, L. Li, F.Y. Yan and L.G. Chen, Spectrochim. Acta A, 73, 789 (2009).

9. X.Q. Zhan, D.H. Li, H. Zheng and J.G. Xu, Anal. Lett., 34, 2761 (2001).

10. K.J. Huang, H. Wang, Y.H. Guo, R.L. Fan and H.S. Zhang, Talanta, 69, 73 (2006).

11. M. Li, H. Wang, X. Zhang and H.S. Zhang, Spectrochim. Acta A, 60 , 987 (2004)

12. S. Kage, K. Kudo and N. Ikeda, J. Chromatogr. B, 742, 363 (2000).

13. A. Jain, R.M. Smith and K.K. Verma, J. Chromatogr. A, 760, 319 (1997).

14. H. Li, C.J. Meininger and G.Y. Wu, J. Chromatogr. B, 746, 199 (2000).

15. J. Hsu, J. Arcot and N.A. Lee, Food Chem., 115, 334 (2009).

16. M.C. Boyce, Electrophoresis, 22, 1447 (2001).

17. C.E. López Pasquali, P. Fernández Hernando and J.S. Durand Alegría, Anal. Chim. Acta, 600, 177 (2007).

18. R. Michalski and I. Kurzyca, Pol. J. Environ. Stud., 15, 5 (2006)

19. P. Griess, Ber. Dtsch. Chem. Ges., 12, 426 (1879).

20. F. Nydahl, Talanta, 23, 349 (1976). 